\title{
Chapter 11 \\ Designing Social Learning Systems for Integrating Social Sciences into Policy \\ Processes: Some Experiences \\ of Water Managing
}

\author{
Kevin Collins
}

\subsection{Introduction}

Let me begin my introduction to this chapter with a short story. As a first year undergraduate, whilst browsing in my university library I came across a book on environmental politics. At the top of one of the chapters was a quote from a United Nations (UN) discussion some decades before about an ongoing policy conflict between two members of the UN. A delegate from another country, exasperated at the intractability of the situation, had stood up in the debate and shouted across the chamber to the two sparring representatives: 'Integrate damn you! Integrate!'. Not appreciating then the importance of maintaining references, I have since been unable to find either where this quote originated or the book it was in - despite many hopeful attempts.

Apart from the lesson of keeping good references, this quote has always stuck in my mind as revealing some essential questions about integration: what is it; who does it; who determines what integrates with what; and under what conditions? Is integration even a choice - an invitation that can be refused? Perhaps most revealing, for the purposes of this chapter, is that the quote does not give much clue as to how the disputing representatives might integrate.

The desire for integration is not in question. Even a cursory review of current lifestyles, societies and policy agendas demonstrates that a desire for integration is now everywhere: especially in technology, society, business and governance. In environmental arenas, integration, at its most basic, and perhaps most challenging, is advanced as the connecting and harmonizing of environmental and human activity to achieve a socially desired state. Integration is used ubiquitously in environmental literatures, policy, and practice and is often the inescapable twin of the equally enigmatic sustainability in all its various forms.

\footnotetext{
K. Collins $(\bowtie)$

Department of Engineering and Innovation, Open University,

Milton Keynes MK7 6AA, UK

e-mail: kevin.collins@open.ac.uk
} 
Integration is intuitively attractive and held up as the key to unlocking and progressing many policy situations in order to achieve sustainability. This is no more evident than the environmental policy 'event of the decade', the Rio +20 conference in Brazil in 2012. Attended by heads of state and government, it is no exaggeration to say that hopes were high that agreements would be reached on a range of issues. With the global media present and watching every move of delegates, it was evident that 'something must be done' to address the lack of coherent policies and disjuncture with practice.

After 12 days of discussions and events, the main outcome was the non-binding document The Future We Want (UN 2012). Throughout, this document emphasized the need for integration of the economic, social and environmental dimensions of sustainable development in a holistic and cross-sectoral manner at all levels.

But the subsequent indications are that Rio +20 was, at best, a political compromise that will achieve marginal gains in some areas, and, at worst, a failure. This rather bleak picture of the state of the political and global environment is all the more notable despite hundreds of international agreements and goals to tackle environmental issues and associated human welfare concerns. A recent report of the United Nations Environment Programme suggests that progress on a range of key issues relating to the Millenium Development Goals such as access to drinking water has been slow and in other areas, such as sanitation or wetland protection, non-existent (UNEP 2012). At the heart of many of these issues is the sense that there has been a failure to integrate social, economic and environmental concerns into policy and practice.

Efforts for integrating natural and social sciences are perhaps more advanced than integrating social science into policy, but, in either case, there is still much uncertainty about what integration actually entails and the methodologies that can be deployed.

This chapter explores some of these concerns in relation to integration and how a praxis (theory informed practice) based on systems and social learning approaches might be used to facilitate integration of the social sciences for policy and practice. In particular, the emphasis is on designing social learning systems as a methodological innovation for integration.

The discussion presented here draws on over a decade of designing social learning systems for engaging with and progressing complex environmental management situations relating to the governance of water resources in different contexts. At the core of this work is an emphasis on epistemological awareness as a means to enable integration of different disciplinary perspectives. The chapter does not discuss in detail the differences within the social sciences that give rise to a lack of integration save to note that all disciplines have their own epistemologies. The approach to integration advocated in this chapter rests on surfacing epistemology and opening up opportunities for social learning. Thus, while the ideas and methodology discussed here have been developed in relation to integration of natural and social science integration, they apply as much to social science integration.

This chapter is divided into seven sections. Following this introduction, Sect. 11.2 explores the framing choices associated with many natural resource policy situations, 
before discussion of the links between integration and systems in Sect. 11.3. In Sect. 11.4, attention turns to social learning and designing social learning systems for integration. Some exemplars of social learning systems are explored in Sect. 11.5. A review of some constraints and opportunities relating to social learning systems is presented in Sect. 11.6. The chapter concludes with a short review of the implications for future research.

\subsection{Framing Choices in Environmental Policy Situations}

Efforts focused on integrating social sciences into policy require an appreciation of the kinds of situations which are encountered by policy-makers, practitioners and scientists of any discipline.

In the runup to Rio +20, the Planet under Pressure conference in London 2012 was notable for its conference declaration that humans have entered the Anthropocene the planetary era defined, for the first time, by human activity where 'many Earthsystem processes and the living fabric of ecosystems are now dominated by human activities' (Brito and Stafford Smith 2012: 2). At the same time, the Global Environmental Outlook report published prior to the Rio +20 conference also endorsed the message of human initiated climate change. In particular, it noted that 'As human pressures on the Earth System accelerate, several critical global, regional and local thresholds are close or have been exceeded. [...] The impacts of complex, non-linear changes in the Earth System are already having serious consequences for human well-being. [...] Because of the complexities of the Earth System, responses need to focus on the root causes, the underlying drivers of environmental changes, rather than only the pressures or symptoms' (UNEP 2012: 9).

Although debates will continue about the primacy or otherwise of anthropogenic climate change, these assessments make two things clear: (1) that our understandings of natural resource management are changing and (2) that understandings and practices that are 'more of the same' are no longer good enough (Schön 1995). At the core of prospects for integration and changing policy and practice is the need to change the way many environmental situations are conceptualised or framed (Schön and Rein 1994). The importance of being aware of how a situation is framed is as true for the social sciences as natural sciences. However, as Redman et al. (2004: 168) observe, while 'most scientists agree that interdisciplinary collaboration is essential [...] our academic training and administrative barriers make that goal difficult to accomplish'. The extent to which the barriers can be reduced depends to some extent on how each discipline within the social sciences seeks to frame the situation through its particular disciplinary lens: whether political; psychological, geographical or economics for example.

Frances (1951) suggests that efforts towards the integration of the different branches in social science requires clarity of epistemological and ontological principles underpinning each of the disciplines (Frances 1951). Scrase and Sheate (2002), in their assessment of integration in environmental assessment, 
identify over 14 meanings of integration prevalent in practice, suggesting that value judgements as much as technical clarity are key to shaping understandings of integration.

Building on these concerns about existing framings, Dovers suggests any understanding of integration as a principle needs to acknowledge spatial and temporal dimensions, disciplinary boundaries, prevailing cultures and the dynamics of social systems, information and knowledge systems (Dovers 1997). In other words, the imperative for integration 'stems from recognition of the interdependence of human and natural systems, expressed in the research and policy agendas of sustainability' (Dovers 2005:3).

In recognising interdependence, the challenge of integration begin to centre on 'development of methods, processes, data streams, and so on to create integrative capacity [which, in turn,] demands a sophisticated understanding of the interactions between highly complex, non-linear, and often closely interdependent human and natural systems' (Dovers 2005: 3, emphasis in original).

Writing from a systems perspective, Ison also extends the boundary of our concern away from individual disciplines within social science, to the situation itself with which social scientists engage, arguing 'the nature of situations cannot be divorced from our own epistemological, theoretical and methodological commitments' (Ison 2008a: 244). In other words, the individual disciplines frame understandings of situations. Efforts for integrating social sciences must therefore pay attention to these framings.

Some possible framing choices include seeing situations either as difficulties or messes (Ackoff 1974); tame or wicked problems (Rittell and Webber 1973); or existing on the high ground of 'technical rationality' or part of the 'swamp' of real life issues (Schön 1995).

The conventional environmental policy paradigm tends to focus on bio-physical systems and frames many natural resource situations as technical issues - ie more as 'problems' or difficulties rather than 'messy situations' (Collins and Ison 2009a). But some examples of re-framing are evident in policy. The Australian Public Service Commission noted that climate change is characterized as a 'wicked problem' because it is

pressing . . . highly complex ..., involving multiple causal factors and high levels of disagreement about the nature of the problem and the best way to tackle it (APSC 2007: 1).

Of particular interest from a methodological point of view, the ASC recognises the need to address 'wicked problems' with approaches that are, among other things, (i) holistic, (ii) innovative and flexible, (iii) work across agency boundaries, (iv) increase understanding and stimulate a debate, (v) engaging of stakeholders and citizens in understanding the problem and in identifying possible solutions; and (vi) tolerate uncertainty and accept the need for a long-term focus. This assessment by the ASC points to the need to understand more clearly how different elements of the situation inter-relate and give rise to the 'messiness'.

Drawing on a tradition of systems in a range of natural resource contexts, including agricultural extension, the EU funded Social Learning for Integrated Management 
of Water (SLIM) project identified a series of system-level characteristics of messy situations comprising: interdependency, complexity, uncertainty, controversy and multiple stakeholdings and thus perspectives (SLIM 2004a; Steyaert and Jiggins 2007). How these characteristics commonly frame a 'messy' situation, and thus what constitutes 'acceptable' responses, can be summarised as:

- multiple stakeholding - where diverse sets of actors actively construct their stake or interest in a situation

- interdependencies - existing when there is little agreement on the boundaries of an issue, or how it will be represented and communicated to others.

- complexity - arising from interdependencies and the diverse cause-effect relationships between local ecosystems, global climate systems and society. It is often linked to partial or complete lack of knowledge about a range of ecological and technical processes and risk (see Skidelsky 2008), social values and wants, and public policy-making imperatives.

- controversies - emerging from an interplay of the previous elements in particular contexts as seen through stakeholders' perspectives and value judgements, traditions of understanding (Russell and Ison 2007), and in the process of constructing their 'stakeholding' (after SLIM 2004b).

These system characteristics and elements combine and are expressed in different ways in different contexts: in some situations, complexity will be associated with data gaps and interpretation of cause and effect; in others complexity could be linked to scale issues or numbers and diversity of stakeholders involved. While it is impossible to pre-determine the exact mix, key to integration in these kinds of situations is epistemological awareness of how those involved in the situation are choosing to frame it. In turn, this can lead to an appreciation of the methodological choices that can be made for managing the natural resource situation in question and in particular what 'integration' among the diverse perspectives might entail.

Arising out of the SLIM project, Ison et al. (2007a) developed the following diagram to depict the importance of being aware of the different kinds of situations and the corresponding methodological approaches that can be chosen as part of the framing of situations.

On the left of Fig. 11.1, the problem is well defined and agreed and therefore a known set of responses, such as education or fiscal measures, can be readily deployed, accepted and used by those involved in this 'difficult' situation. On the right hand side, the situation is indeterminate (as shown by the incomplete boundary). The 'messy' situations extant on the right hand side of Fig. 11.1 can be seen in many natural resource policy contexts and are often evidenced by uncertainties about the nature of the situation itself; concerns about data gaps; and disagreements among stakeholders about what effort is required and how it should be focussed, to name but a few.

Where uncertainties, interdependencies and complexities are experienced, natural resource managing cannot be done by one or two actors in isolation. Instead, it requires a range of views and perspectives to be engaged in defining the situation and issues and determining an approach which is context relevant. 
a

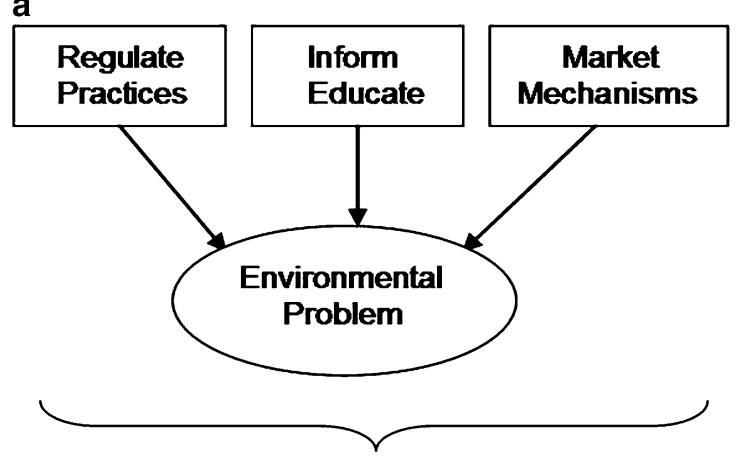

Fixed form of knowledge
applied to a problem b

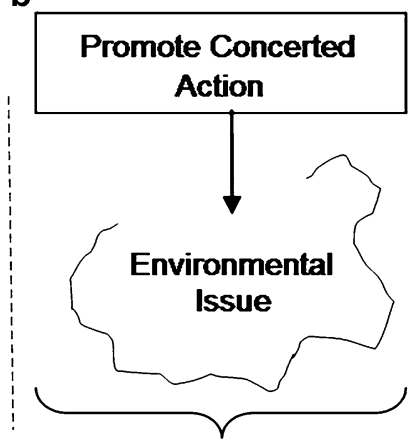

Designing social learning systems for adaptation

Fig. 11.1 The epistemological basis from which social learning for promoting concerted action can be developed as a purposeful choice. In (a), a known and agreed problem can be addressed by stakeholders using a known form of knowledge. In (b), social learning systems are required to determine responses to contested and incomplete understandings of the environmental issue (After SLIM 2004a; Ison et al. 2007a; Collins and Ison 2009b)

Appreciation of the characteristics of the situation through some form of learning can provide opportunities for a re-framing of the situation to enable integration of different disciplines.

The potential contribution of social science to the re-framing of research was explored by an EU expert group exploring research required for sustainable development. This group noted that:

social scientists studying how research results get used or ignored in policy systematically come to the conclusion that a linear process does not work: there is not a clear domain of science, that produces knowledge, that feeds into or 'impacts' upon a separate system of policy. Rather, there is a set of multiple forms of knowledge, including a variety of research fields, which have to relate to a variety of policy areas and specific policies. (Anon 2007: 4)

Atkinson and Klausen's (2011) review of EU policies provides a similar assessment of integration. They note a 'high degree of comprehensiveness is necessary in order to accommodate concerns for the social and economic aspects of sustainability, not just the environmental aspects.' With this widening of concerns, however, they suggest consistency and aggregation are diminished leading to a well-known policy dilemma: "the more aspects of an issue policy makers attempt to take into account, the more difficult it is to aggregate these aspects into a consistent policy' (246).

This perspective makes clear that while integration may be widely supported as an ideal principle in order to bring about improved policy and practice, a linear conceptualisation of the process of knowledge and practice, as typified by an emphasis on science - policy - action, will always be deficient as a means to enable 
integration of social science. Furthermore, an aggregation model of integration is conceptually and methodological flawed as policy-makers will struggle to cope with, literally, the added complexity.

These imperative of integration, constraints of framing and criticisms of linear policy suggest an alternative, more systemic conceptualisation of, and methodology for, integrating social science into policy is required. The potential for integrated natural resource managing from a systems perspective is explored next.

\subsection{Integration and Systems}

Integration is not a straightforward and linear task as might be implied by disarming phrases such as 'joined up thinking', 'adding' 'connecting' or indeed Wilson's 'jumping together' (Wilson 1998: 8).

Etymologically, integration comes from the Latin integrare - to make whole. Integration can be defined as the 'making up or composition of a whole by adding together or combining the separate parts or elements'; and 'combining of diverse parts into a complex whole' (OED 2012). In other words, integration is the process of making wholes.

The emphasis on making wholes is a fundamental aspect of systems theories and concepts. But what do we mean by system? Returning to etymology, the word system is derived from the Greek verb synhistanai meaning 'to place together'. According to the systems writer, Russell Ackoff, a system is

a whole that cannot be divided into independent parts. [...] The essential properties of a system taken as a whole derive from the interaction of its parts, not their actions taken separately. (Ackoff 1981: 64-65)

Peter Checkland, the systems writer, also emphasises the importance of the whole in understanding systems: 'the central concept 'system' embodies the idea of a set of elements connected together which form a whole, this showing properties which are properties of the whole, rather than properties of its component parts' (Checkland 1981: 3).

Thus a system can be described as 'a whole' comprising interdependent parts. With this simplified, but powerful understanding, the fundamental conceptual link between systems and integration becomes evident: integration is the making of wholes or systems. In terms of methodology, the question then presents itself as: what methodological innovation can enable the making of wholes among diverse disciplines, including the social sciences, in policy contexts?

Before exploring some possible answers, it is important to be aware that integration does not automatically convey some positive quality to the system: not all systems and not all integration are positive or socially desirable. For example, an illegal waste system which ships and dumps waste computers from the EU into Africa, may be a highly integrated system, but one which, in this particular case, is considered socially undesirable and illegal. 
Thus, from a systems point of view, integration, of itself, does not carry a value judgement in terms of ethics or outcomes, although of course evaluating the work done by the system may involve a wide range of measures of performance, including ethical considerations. In this sense, integration is a somewhat neutral concept - the definition and arrangement of the system for particular purposes by particular stakeholders determines whether integration achieves socially acceptable goals.

It is also important to be aware that any discussion on systems quickly reaches a point where an epistemological choice has to be made: do we see systems as 'out there', existing in the real world, or do we see systems as more observer dependent? This distinction is often linked to distinguishing between 'hard' systems which are claimed as an ontological reality and 'soft' systems (Checkland 1981) where emphasis is on the constructed nature of a system, dependent on the observer defining a system boundary. The different debates about these branches of systems and consequences for knowledge and knowing are not rehearsed here. Indeed, as Ison (2008b) suggests, the distinction between hard and soft systems has tended to create a dualism - a selfnegating pair - rather than a duality - a connected and interdependent complementarity. It is, however, notable that the 'soft systems' tradition is more aligned to qualitative framings and methodologies which find resonance in the social sciences and for this reason the focus of this chapter remains on soft systems.

A central aspect of the soft systems perspective is raising awareness of the different boundary choices by different stakeholders in a situation. In this tradition of systems, it is accepted that stakeholders 'see' and value different elements and thus their boundary choices relating to their chosen system will vary. The choices of system boundary and system elements are fundamentally linked to the purpose ascribed to any system by the observer. Thus, within soft systems, a system can be described as 'a whole defined by someone as having a purpose'. The term 'system' is used as a shorthand for 'system of interest'- ie an observer-dependent formulation of what constitutes a whole made up of interdependent parts.

For example, within the same water catchment, a farmer's system of interest might comprise elements such as crop types, water supply, markets, land-use, financial concerns and family needs. A conservationist's system of interest in the same catchment might be local species, habitat and the river ecology. A business offering canoe trips in the catchment might be mostly concerned about river levels, water quality, habitat and access rights. Each stakeholders' system of interest may overlap in terms of having shared elements (eg the river), but this does not mean each system of interest is integrated with the others. Indeed, it is the sense in which these different systems of interests are experienced as competing rather than integrating, that gives rise to a sense of divergence of goals, controversy, disintegration of action and environmental loss.

The emphasis on wholes is an important conceptual framing in systems thinking, alongside the irreducibility of a system's characteristics to its component parts: ie a system cannot be reduced to its component parts. This has particular implications for the way we conceptualise integration. In short, integration is not a thing that can be applied to a situation. Rather, integration is a system-level property that emerges from the interaction and inter-dependencies of the different elements of the system. 
This may seem self-evident, but its consequences are profound: integration cannot be applied to a situation of natural resource management by researchers (of any discipline), policy-makers or practitioners. Integration arises at the systems level ie from the set of interactions between the different elements identified by someone as being part of the system. With this insight, the focus shifts away from trying to 'add' integration as some kind of ingredient into policy process which can be applied to a specific aspect, policy process or part of a situation. Instead, considerations centre about how to create the system-level conditions in which integration emerges.

Within this view of systems, natural resource management praxis is extended beyond the confines of engineering and biophysical science disciplines and into social sciences. Integration, understood as the making of wholes and an emergent property of systems, coupled with an emphasis on observer dependency, leads to the view that natural resource managing is fundamentally a social process. Methodologies are needed which recognise and engage with the social element and also the process element and which also recognise the complexity, controversy and multiple stakeholding in the way situations are framed. Drawing on exemplars from water resource managing, attention now turns to designing social learning systems as a key means to integrate social sciences into policy processes and outcomes.

\subsection{Designing Social Learning Systems for Social Science Integration}

Social learning is not a new idea or concept and its lineage can be traced in various literatures across social science branches including psychology, criminology, education and business studies. The concept is often linked to Bandura's work on social theory of learning (Bandura 1977) where individual learning takes place in a social context. Blackmore's (2007) review of social learning theories notes that social learning is likely to be interpreted and defined in accord with different theoretical traditions and interpretations. Of relevance to the discussion on natural resource managing, Blackmore also notes that social learning theory is part of the tradition of 'adaptive management' (Holling 1978) and is linked to Wenger's social theory of learning in communities of practice: defined as 'groups of people who share a concern, a set of problems, or a passion about a topic, and who deepen their knowledge and expertise in this area by interacting on an ongoing basis' (Wenger et al. 2002: 4-5; see also Wenger 1998).

With such origins and lineage it is perhaps not surprising that in the last decade there has been considerable attention from a range of authors in social learning for environmental managing (see Social Learning Group 2001) and in particular water resources (see, for example, Finger and Verlaan 1995; Daniels and Walker 1996; Woodhill and Röling 1998; Collins et al. 2007; Ison et al. 2007a, 2011; Pahl-Wostl et al. 2007; Pahl-Wostl et al. 2007, 2008; Mostert et al. 2007; Muro and Jeffrey 2008; see also Reed et al. 2010; Raadgever et al. 2012). The detailed distinctions and different interpretations of social learning by these authors are not rehearsed here. 

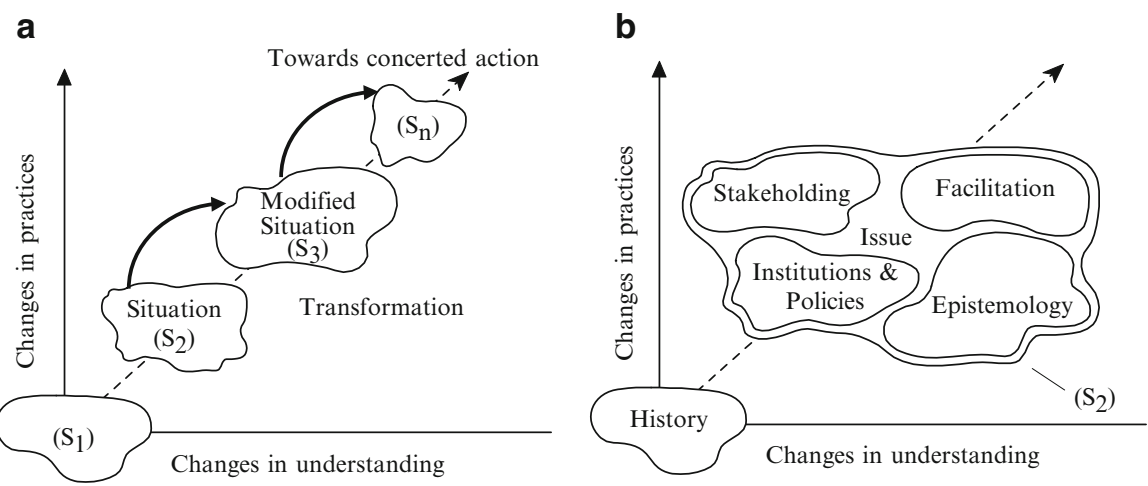

Fig. 11.2 A heuristic for social learning. (a) Social learning in complex, uncertain and contested situations over time enables transformation through changed understandings and practices leading to concerted action by stakeholders. (b) The SLIM social learning heuristic depicts how six key variables interact to shape issues and particular situations. These variables include history, stakeholding, facilitation, institutions and policies, and epistemology (After SLIM 2004a; Ison et al. 2007a)

Instead, the definitions of social learning developed by the previously mentioned SLIM project were used as the conceptual and methodological basis of the case studies reported below. In the SLIM project, social learning came to be understood as one or more of four potentially inter-related processes:

(i) the process of co-creation of knowledge, which provides insight into the history of, and the means required to transform, a situation;

(ii) the convergence of goals (more usefully expressed as agreement about purpose or purposes), criteria and knowledge leading to awareness of mutual expectations and the building of relational capital;

(iii) the change in behaviours that results from the understanding gained through doing ('knowing') that leads to concerted action; and

(iv) arising from these, social learning is thus an emergent property of the process of transforming a situation (SLIM 2004c, d; see also Ison et al. 2007a; Collins and Ison 2009a, b).

Social learning is thus based on the process of multiple stakeholders socially constructing an issue in which their understandings and practices change so as to transform the situation of concern. This interpretation of social learning refers to collective learning - ie learning at the system level - in a social context compared to Bandura's individual learning in a social context

A diagrammatic depiction of the process of social learning is shown in Fig. 11.2. The axes represent the relationship between changes in the situation ( $\mathrm{s} 1 \rightarrow \mathrm{s} 2$ etc.) arising from changes in understanding and action and the process of transformation over time. The key elements relating to the transformation process are shown: starting context; institutions; facilitation; stakeholding and epistemological constraints. 
Appreciating the starting context is important so as to become aware of legacies, framings and previous experiences of those involved which may have led to previous actions, divisions, conflict or opportunities for new practices in the current situation. The institutions element is broadly interpreted and concerns those aspects of a situation which enable or constrain behaviours and practices such as laws, regulations, policies, organisations, traditions and customs. The element titled as facilitation is also broadly interpreted and refers to people, activities and/or things which enable stakeholders to engage in conversations and inquiry. This can be a professional facilitator but it can also involve some intermediary object (see Steyaert et al. 2007) around which new debates and practices are focussed. Instead of the more usual reference to stakeholder, the heuristic specifically refers to stakeholding to note that individuals actively construct their stake and that this can be changed as a result of engaging with others in a social learning process.

The final element refers to epistemological constraints. In the original SLIM work (see SLIM 2004e) this was titled as 'ecological constraints' as it was noted that there were often diverging and competing understandings and conceptual models of ecology in many natural resource management debates. The SLIM researchers later reworked this, expanding the title of this element to 'epistemological constraints' or 'epistemology' to denote that all conceptual models and ways of knowing from any disciplinary branch (including social sciences) or praxis could constrain the way the situation is experienced and understood.

The key aspect of this diagram is that it is intended as a heuristic rather than prescriptive model of social learning - what occurs within each element and the configuration and 'weighting' of each will vary according to specific context.

Within a social learning paradigm a priority in research practice is to know how to create the circumstances for social learning to occur - ie designing a social learning system. The heuristic depicted in Fig. 11.2 reveals that in social learning, the inquiry moves away from routine or first order learning, by questioning starting assumptions and making sense of context, thus revealing the second order framings used by stakeholders in the situation as they engage with epistemological differences. A social learning system should enable those involved, whether social scientists, scientists, policy makers and practitioners, or any combination thereof, to question framings, norms, policies and objectives in interactive processes involving multiple stakeholders.

In emphasising social learning, integration of social science in policy-making becomes centred on a concern about designing social learning systems (see Ison et al. 2007b) for natural resource managing, as a way of integrating different disciplines within social science to enable contributions to policy processes.

The work undertaken as part of the SLIM project found that to create the conditions for integration to emerge, a social learning system should have the following characteristics:

- Systemic features

- Comprises elements or activities

- Exhibits connectivity 


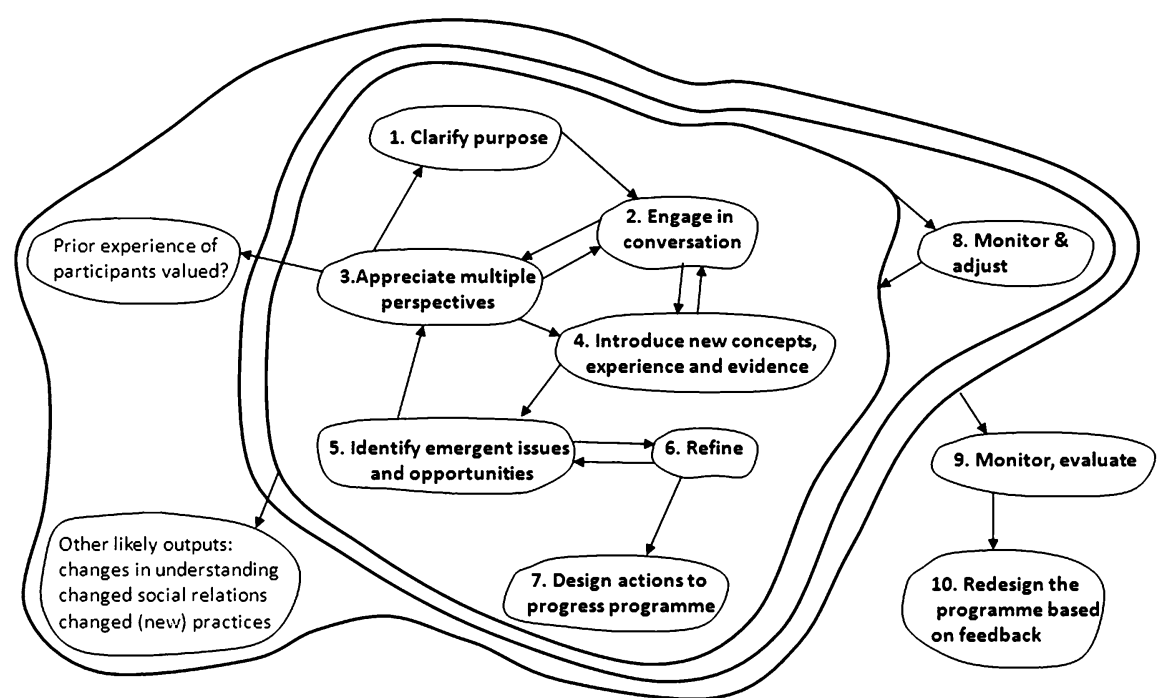

Fig. 11.3 Design for a social learning system in complex natural resource management situations (After Ison et al. 2009)

- Results in transformation

- Has emergent properties

- Is bounded in some way

- Design/designer features

- It is purposeful to those who participate

- It is not deterministic

- The 'designer' is aware that what is valid knowledge is contested.

This listing set out meta-level criteria for design that require more detailed interpretation in relation to specific contexts. One example of a how the meta criteria for design might be enacted as a social learning system is given in Fig. 11.3.

The design in Fig. 11.3 builds on the SLIM heuristic shown in Fig. 11.2 and sets out the key activities which can give rise to social learning. The first activity - clarifying purpose - emphasises the need for those involved in the design and process to be explicit about the purpose of engaging in the learning process. This is an iterative process which requires others to be engaged in the conversation (activity 2) and a (collective) appreciation of a range of stakeholders' views and perspectives (activity 3). As the process continues, new ideas, information and experiences can be introduced to help determine the situation more clearly and understand different framings. The exact means by which this is done varies according to context and need - in some cases a workshop bringing together social scientists and policy makers might be convened, in other instances, it might involve meeting with river managers on a river bank to understand their practices, concerns and framings of the situation. Methodologically, the aim is to enable conversations which enable participants to appreciate the multiple 
perspectives of those involved in the situation. The emphasis on appreciation is not just a requirement upon the researcher, but extends to all those in engaged in the learning system in that all participants 'sign up' or agree to this way of working.

Arising from the interplay and iteration of activities 1-4, issues and opportunities for progressing the situation begin to emerge and are refined over time (activities 5 and 6). This leads to developing agreement on a set of actions which can be enacted by individuals and/or organisations as appropriate. At this point, the performance of the learning system can be evaluated by recourse to a monitoring process (activity 8). The format of the monitoring process can again vary according to context, but to be consistent with the design of the learning systems, should have input from those involved in the process for determining performance criteria. This is particularly the case with the outputs from activity 3 which requires that the prior experiences of participants are valued in the learning process. Arising from activities 1-8, expected outputs of the learning system include changes in understanding, changes in relations between participants and new concerted practices as part of the transformation of the situation (see Fig. 11.2). It is in these outputs that integration of knowledges and integration of practices (as concerted action) emerges. Activities 9 and 10 relate to monitoring the performance of the learning system and its outputs and re-designing as appropriate.

The SLIM heuristic (Fig. 11.2) and the learning system show in Fig. 11.3 have been used in conjunction for researching and enabling social learning in various contested water resource situations by the author and colleagues from several institutions over the last decade. Aspects of some of this research in the UK, Australia and China provides some insight into the issues associated with designing social learning systems for progressing integration of social sciences into resource managing in different contexts.

\subsection{Case Studies of Designing Social Learning Systems}

The following account of the various case studies is not intended to be an extensive and detailed description of the individual case studies. Instead the aim is to draw out those aspects which shed light on the design of social learning systems. As noted above, not all of this work involves social science, but the general principles and experiences are of direct relevance to the inquiry about social science integration into policy.

\subsubsection{Integrating Environment Agency Catchment Science into Policy}

The first case study, which took place after the SLIM research mentioned above, centred on co-research beginning in 2006 with the Catchment Science group of the Environment Agency (EA) of England and Wales. The aim was to facilitate integration of a range of physical sciences with policy imperatives to progress 
implementation of the EU Water Framework Directive within the EA's science activities. Recognising the disparity between the different sciences, the aim of the research was to design a social learning system for the catchments scientists within the EA to enable them to integrate their different disciplinary perspectives and to contribute to the effective design of policy.

The work began by focussing upon clarification of purpose. This was done using a range of systems diagramming techniques to explore context and different conceptual models of catchment science (relating to epistemology in the SLIM heuristic). During the first workshop with the catchment scientists, it quickly became apparent that there was no shared conceptual framing of integrated catchment management or catchment science within the Science Group or across the EA as a whole or indeed the wider literature. It was also apparent that there were marked differences between scientists and policy makers as to defining their various roles and responsibilities: each thought the other should follow them.

A learning system was designed to work through the issues with the Science Group centred on a series of workshops over 18 months in which the nature of integrated science and the relationship between policy and science was explored in some detail. The research is described in more detail elsewhere (see Collins and Ison 2010).

Despite best intentions and commitment to learning, the scientists found it difficult to find ways to integrate their different sciences. Debates continued on which particular scientific discipline was the most important to understand catchments. Significant progress on integrating the sciences was only really achieved when it was realised by some members of the group that the science needed to be discussed in relation to policy. Policy-makers were then invited into the process and the social learning started anew, this time exploring how different framings of science and catchments were constraining or enabling integration of science and policy.

The research ended earlier than anticipated for a variety of institutional reasons, including organisational changes and personnel shifts. Even so, a key finding was that integration of the different scientific disciplines only really became possible at the level of, and in relation to, policy objectives rather than the level of scientific disciplines themselves. This is consistent with understanding integration as an emergent property of a system - in this case a system to develop integrated catchment science and policy. It also highlights the futility of expecting the sciences (whether physical or social) to be able to provide or pre-specify integration as a precursor or 'ingredient to' policy. Instead, for integration into policy to occur, sciences need to be reconceptualised not as the determinant of policy or receiver of policy, but as part of the system of managing for emergence of integration in natural resource managing.

\subsubsection{Creating Water Sensitive Cities in Australia}

The second case study vignette relates to research initiated to progress capacity building and shared understanding for Transitioning to Water Sensitive Cities in Australia - a notion that urban areas need to be more adaptive to a climate 
changing context and thus reconceptualise the relationship between a city and its hinterland. The research was the result of a partnership between the International Water Centre (IWC) and the National Urban Water Governance Program (NUWGP) and Monash University. A series of five national workshops, each of 2 days, were held in each of the state capitals during early 2009. The workshops involved over 500 participants from the water sector, ranging from policy-makers, practitioners and researchers from many different physical and social science disciplines. The workshops were designed and conducted as a 2 day social learning process, broadly based on the process depicted in Fig. 11.3. Again, based on systems concepts and diagramming techniques, the workshop design aimed to identify the following: issues and opportunities that enable or constrain transitioning to water sensitive cities; characteristics of water sensitive cities from participants' perspectives; priority actions required in each city; and personal enthusiasms for action.

To some extent the generic aims are perhaps common to many workshop processes. However, in this case, the design and the methodological techniques used ensured that participants engaged with each other at an epistemological level to reveal and learn about multiple framings, prior to discussions about the system of water governance in Australian cities, issues and actions to be taken. In other words, the design of the workshops aimed to surface second order as well as first order concerns and develop a water governance system based on the social learning emerging during the workshop.

The detailed findings are reported elsewhere (see Ison et al. 2009), but feedback from the workshop evaluations suggest that the learning design of the workshops enabled participants' multiple perspectives to be heard and contribute to an understanding of the issues and thus avoid a limited set of approaches and views from dominating. In summary the shifts reported by a majority of participants included:

(i) a substantial development in the conversations about water sensitive cities at interpersonal, inter- and intra-departmental and inter-organizational levels;

(ii) changes in conception about water sensitive cities;

(iii) embryonic changes in policies at, mainly, departmental levels;

(iv) increased advocacy by a wide range of stakeholders for policy and practices to move to water sensitive cities. (see Ison et al. 2009; Collins et al. 2009)

Some caveats are important to note. The longer terms effects of this research are still be judged as it was not possible to assess these within the research time frame. Also, the research involved many different disciplinary traditions in the engagement with policy. While it is not possible to comment on the social sciences per se, by extension, the potential for integration of the social sciences into policy is evident from the reported findings. With these caveats, it seems reasonable, on the early reporting from the workshops, that the learning design of the process represented a significant opportunity for participants to recognise different framings of the situation from multiple perspectives and thus engage in new conversations to help integrate research, policy and practice. 


\subsubsection{Social Learning for Ecosystem Services in Lake Baiyangdian, China}

This research work in 2010-2011, funded by the UK research councils, was undertaken as part of wider research programme exploring the potential of managing ecosystems services as a means of poverty alleviation. Baiyangdian catchment lies in the middle of the North China Plain and is home to almost 700,000 people officially recognised as living in poverty. A large catchment area of $31,200 \mathrm{~km}^{2}$, historically with nine rives, Lake Baiyangdian is the largest remaining semi-closed freshwater body in the northern part of China. As a result of industrial expansion and increased water use for agriculture to supply Beijing, rivers have dried up and the surface area of the lake greatly reduced with inevitable degrading of the catchment ecosystem and livelihood implications for the population.

Using a variation of the heuristic framework described earlier, a cross-disciplinary research group of ten scientists designed a process of inquiry involving researchers from science and social science backgrounds, working with managers and community groups in Lake Baiyangdian to engage in a social learning process about the history, context, and framings of issues in the catchment. A week long inquiry involving workshops, interviews and field visits was designed to be open to local contexts, allow for emergence of new insights from a range of actors with different geographical, organisational and political links; and to generate systemic understanding of the situation through social learning among those involved.

The detailed description of the work and the findings are reported in Wei et al. (2012). In terms of the present discussion, the findings reveal the limitations of current framings of Lake Baiyangdian water management, dominated by particular framings of nature, ecology and ecosystems that are considered manageable through engineering, understood as 'good practice' in Chinese water management. Insights from the social learning process were gained in several areas, including (i) understanding the diversity of participants' perspectives of the situation and how the disciplinary training and institutional framings of the researchers and policy-makers shaped their suggested focus for improving the catchment; (ii) opportunities and potential to progress water managing through the purposeful design and enactment of a catchment managing learning system; and (iii) that the lake could become a focus or 'mediating object' to enable new conversations about ways to transition to more ecologically sensitive decision making and greater social and institutional resilience.

Mindful of the particular cultural context, careful attention was paid to good process design, the presence and expression of stakeholders (including cultural outsiders), valuing multiple partial perspectives and effective facilitation - all key requirements if a more sustainable managing of the catchment is desired. As with the other cases reported above, social science integration was not a deliberate focus, but the design of the learning process was able to accommodate a wide range of physical and social science perspectives throughout the process, particularly when engaging with policy making in an attempt to facilitate new framings of the situation. 
These examples are just some of the action research situations where designing a social learning system has been advanced as an appropriate conceptual and methodological innovation to bring about more integrated resource management which recognises the importance of both biophysical and social science. In the next section, we explore some limits and opportunities for designing social learning systems as means to enable integration of social science into policy.

\subsection{Constraints and Opportunities for Social Learning for Integration}

The opportunities and limitations of a learning approach to policy integration are still being discovered and appraised as more research in this area is undertaken. Within a social learning paradigm a priority in research practice is to know how to create the circumstances for social learning to occur as part of a learning system.

Perhaps surprisingly for readers of this volume, the constraints do not include difficulties associated with integration - even if this is an element perceived as a constraint by others engaged in natural resource management situations. The reason for this is because, from a systems perspective, integration is not the primary concern. Instead, in designing a social learning system, the focus is on how to create the conditions for enabling social learning for resource managing, from which integration of the different sciences with policy can emerge. However, there are several constraints which can undermine the potential for a learning system to function effectively and thus reduce the likelihood of integration. As noted above, these do not focus on social sciences explicitly since the constraints apply to the design of social learning systems.

The first constraint - and perhaps the meta constraint of social learning processes since it affects all others - is very simple to describe: trust. Understanding what leads to trust for multiple stakeholders and designing and creating the circumstances for trust is less simple. Both the social and the learning element of social learning systems require a level of trust to begin and continue the engagement with others which leads to action. Stakeholders' prior experiences and assessments of the usefulness, quality and likely outcomes of the current learning process (including any facilitation) will be significant factors in shaping trust. Hence, a key criterion for designing any social learning process can be summed up with the question: does this process and its constitutive elements contribute to or constrain the establishment and continuation of trust amongst participants and stakeholders? Answers to that question will vary widely according to context and stakeholders' varying perspectives. Developing the answers provides an opportunity for social sciences to contribute to the substantive content in understanding the situation in terms of trust as well as the design and evaluation of learning systems for NRM.

Linked to trust, and particularly important in terms of initiating social learning, there is often a significant time element in initiating and managing social learning processes. This extends to reporting on social learning processes where the changes 
arising from social learning might take several years to manifest, if at all. Time frames and lags can be especially problematic if the proposed initiative is seen as 'unusual' or 'threatening' or in some way counter to organisational remits, practices which are centred on wanting answers 'in the short-term'.

Allied to time constraints, the emphasis in social learning processes on participants being part of the co-research process brings a range of commitments and responsibilities which may not align easily with expectations.

This can be most evident in the difficulties of the researcher retaining epistemological awareness and avoiding being assigned the label 'consultant' and its ramifications, particularly the expectation of 'coming up with the answer' to policymakers' questions. Designing a social learning system begins more with the participants 'coming up with a question'. This shift in thinking and practice required within a social learning process in the praxis of research and policy can be resisted by others who are keen (and under pressure from, for example, their organisations or funders) to find the solution, even though the nature of the situation has yet to be adequately defined. Added to this is that many organisations function with adherence to project management tools, such as PRINCE, which can fail to acknowledge or deal with messes and uncertainties and constrain efforts to move beyond projects as technical events.

Scale issues continue to be an issue for social learning processes. For example, how to move from localised, catchment level initiatives where trust can be built and actors have direct stakeholding, to wider, regional or national scales of policymaking. A systems approach can accommodate scale on the basis that any system of interest can also be a sub-system of a wider set of concerns. Thus a nested conceptualisation of systems for natural resource managing is possible. Even so, individual relationships, contact and commitments necessary for trust are difficult to establish and maintain across different levels of policy-making unless there is good awareness and understanding amongst those involved. Quite what this entails and how it can be enacted is context dependent, but design considerations should be led by earlier questions about trust.

The issue of scale also brings a compelling research question to the fore which positions policy-making as just one aspect or sub-system of a natural resource managing system. With such a view, the question becomes less 'what is the right scale?' and more 'what is the right knowledge and governance system for managing a particular resource'? This question address scale, but not as the determining factor, and frees up ways of connecting different scales as part of the social learning process.

This brief discussion on some constraints to social learning encountered also point to some opportunities for bringing methodological innovation into natural resource managing.

Perhaps the most important is skills development in systems thinking and practice such that researchers, policy-makers and practitioners are aware of how their histories, contexts and disciplinary training shape their understanding of a situation and the choice of management methods they deploy. Such epistemological and methodological awareness is key to moving from first to second order thinking. 
An opportunity also presents itself in that the limits of participation as the means to achieve integration of multiple perspectives in situations of natural resource managing are increasingly recognised. As Collins and Ison (2009b) argue, participation is a necessary element of, but not sufficient for social learning to occur. This is because social learning is epistemologically different to participation.

Combining these two opportunities, perhaps a key opportunity for social science integration rests on the engagement with and reconceptualization of the social and the biophysical systems in natural resource managing. The notion of social-ecological system is explored widely in the literatures (see for Berkes et al. 1998; Folke et al. 2005; Armitage et al. 2009; Young 2012). Much of this literature explicitly calls for a reframing of the society-nature relationship, often associated with some element of learning. This reframing requires a new understanding of the relationship between biophysical sciences and social sciences where it is not a self-negating 'either/or' dualism, but a complimentary duality - ie each part contributing to a whole (see Collins and Ison 2009a). This brings us back to the beginning of the discussion on integration - defined earlier as the making of wholes. Contributing to the understanding of the duality (or the whole) in socio-ecological systems will be key to the ways in which social sciences can integrate into policy and become a central part of social learning systems for natural resource managing.

\subsection{Concluding Comments and Implications for Future Integrated Policy-Making}

This chapter has aimed to provide an account of a methodological innovation centred on designing social learning systems for integrating social science into policy.

The discussion on framing points to the possible framing choices available to scientists and policy-makers. The characteristics of messy natural resource management situations centred on interdependency, complexity, uncertainty, controversy and multiple stakeholdings suggest that no one individual or organisation is able to manage in isolation. Engaging with framing choices leads to epistemological awareness which is a key step towards integration.

Appreciating NRM situations as complex and 'messy' opens up possibilities for a complimentary methodological approach based on systems. Although much has been written on integration, it remains elusive as a concept and practice. However, the discussion on the link between integration and systems reveals their fundamental connection in that both are central to the process of 'creating wholes'. Within a soft systems tradition, the importance of boundary choices (a form of framing) is key to understanding different perspectives. A systems view also gives rise to the idea of integration as an emergent property of a system, rather than a 'thing' that can be added. The central concern then for integration of social science into policy is creating and thus designing system level conditions for integration as an emergent property of social learning systems. Integration of social science per se becomes less important than a concern with designing social learning systems from which integration emerges. 
Integration, understood as the making of wholes and an emergent property of systems, coupled with an emphasis on observer dependency, leads to the view that natural resource managing is fundamentally a social process. In this framing, the imperative for social learning - understood as the process of stakeholders socially constructing an issue in which their understandings and practices change so as to transform the situation of concern through concerted action - becomes clear.

The key elements relating to the transformation process include an appreciation of the starting context; institutions; facilitation; stakeholding and epistemological constraints.

The vignettes of the case study research point to ways in which social learning systems can be designed and enacted in a variety of NRM situations and contexts, although the exact detail is beyond the scope of this chapter. Perhaps the key design criterion relates to ways in which trust is established and developed over time.

The discussion of some constraints and opportunities associated with a social learning approach as an innovative methodology for integrating social sciences into policy is only the beginning of our understanding as more research on social learning becomes available. But it would seem that social sciences has much to offer in terms of substantive content to natural resource managing as well as research on the design, process and evaluation of social learning processes.

A note of caution is necessary, however, as designing and enacting social learning systems requires epistemological, temporal and financial investment from policymakers and scientists from all disciplinary backgrounds. It also requires developing skills and competency in systems concepts and ideas - not least integration as an emergent property of a social learning system and all that this entails for policy and science processes.

Looking forward, integrating social science into policy through a social learning systems is not a given. It requires commitment and willingness to engage in second order concerns about the nature of knowledge and understanding of complex, messy situations. The increasing use and acceptance of the concept of socio-ecological system as a coupled, co-evolving system would seem to be a central arena for future research. It is here that designing social learning systems as a methodology for enabling integration of social science with policy and biophysical sciences is likely to be of most import.

Open Access This chapter is distributed under the terms of the Creative Commons Attribution Noncommercial License, which permits any noncommercial use, distribution, and reproduction in any medium, provided the original author(s) and source are credited.

\section{References}

Ackoff, R. L. (1974). Redesigning the future. New York: Wiley.

Ackoff, R. L. (1981). Creating the corporate future. New York: Wiley.

Anon. (2007). Research for sustainable development: how to enhance connectivity? Report of an EC Workshop, Brussels, 7-8 June 2007. Background paper by expert group for Research and 
Development for Sustainability (RD4SD). Available at: http://ec.europa.eu/research/sd/pdf/ background_info/report_halfman.pdf. Accessed 18 Nov 2012.

APSC (Australian Public Services Commission). (2007). Tackling wicked problems. A public policy perspective. Canberra: Australian Public Service Commission.

Armitage, D. R., Plummer, R., Berkes, F., Arthur, R. I., Charles, A. T., Davidson-Hunt, I. J., Diduck, A. P., Doubleday, N. C., Johnson, D. S., Marschke, M., McConney, P., Pinkerton, E. W., \& Wollenberg, E. K. (2009). Adaptive co-management for social-ecological complexity. Frontiers in Ecology and the Environment, 7, 95-102.

Atkinson, R., \& Klausen, J. E. (2011). Understanding sustainability policy: Governance, knowledge and the search for integration. Journal of Environmental Policy \& Planning, 13(3), 231-251.

Bandura, A. (1977). Social learning theory. Englewood Cliffs: Prentice Hall.

Berkes, F., Folke, C., \& Colding, J. (1998). Linking social and ecological systems: Management practices and social mechanisms for building resilience. Cambridge: Cambridge University Press.

Blackmore, C. (2007). What kinds of knowledge, knowing and learning are required for addressing resource dilemmas? A theoretical overview. Environmental Science and Policy, 10(6), 512-525.

Brito, L., Stafford Smith, M. (2012, March 26-29). State of the planet declaration. In Planet under pressure: New knowledge towards solutions conference, London. Available at www.planetunderpressure2012.net/pdf/state_of_planet_declaration.pdf. Accessed 10 Apr 2013.

Checkland, P. (1981). Systems thinking, systems practice. New York: Wiley.

Collins, K. B., Ison, R. L. (2009a). Living with environmental change: adaptation as social learning. Environmental Policy \& Governance, 19(6), 351-357. (Editorial, special edition)

Collins, K. B., \& Ison, R. L. (2009b). Jumping off Arnstein's ladder: Social learning as a new policy paradigm for climate change adaptation. Environmental Policy \& Governance, 19(6), 358-373.

Collins, K. B., \& Ison, R. L. (2010). Trusting emergence: Some experiences of learning about integrated catchment science with the environment agency of England and Wales. Water Resources Management, 24(4), 669-688.

Collins, K., Blackmore, C., Morris, D., \& Watson, D. (2007). A systemic approach to managing multiple perspectives and stakeholding in water catchments: Some findings from three UK case studies. Environmental Science and Policy, 10(6), 564-574.

Collins, K. B., Colvin, J., \& Ison, R. L. (2009). Building 'learning catchments' for integrated catchment managing: Designing learning systems and networks based on experiences in the UK, South Africa and Australia. Water Science \& Technology, 59(4), 687-693.

Daniels, S., \& Walker, G. (1996). Collaborative learning: Improving public deliberation in ecosystem-based management. Environmental Impact Assessment Review, 16, 71-102.

Dovers, S. (1997). Sustainability: Demands on policy. Journal of Public Policy, 16, 303-318.

Dovers, S. (2005). Clarifying the imperative of integration research for sustainable environmental management. Journal of Research Practice, 1(2), Article M1. Available from http://jrp.icaap. org/index.php/jrp/article/view/11/30. Accessed 15 Oct 2012.

Finger, M., \& Verlaan, P. (1995). Learning our way out: A conceptual framework for social-environmental learning. World Development, 23, 505-513.

Folke, C., Hahn, T., Olsson, P., \& Norberg, J. (2005). Adaptive governance of social-ecological systems. Annual Review of Environmental Resources., 30, 441-473.

Frances, E. (1951). History and the social sciences: some reflections on the re-integration of social science. Review of Politics, 13(3), 354-374.

Holling, C. S. (Ed.). (1978). Adaptive environmental assessment and management. Chichester: Wiley.

Ison, R. L. (2008a, Oct 29-31). Understandings and practices for a complex, coevolutionary systems approach. In: Proceedings of the international symposium: Selected topics on complex systems engineering applied to sustainable animal production, Instituto Tecnolo del Valle de Morelia, Morelia, Michoac, Mexico.

Ison, R. L. (2008b). Methodological challenges of trans-disciplinary research: Some systemic reflections. Natures Sciences Societes, 16(3), 241-251. 
Ison, R. L., Röling, N., \& Watson, D. (2007a). Challenges to science and society in the sustainable management and use of water: Investigating the role of social learning. Environmental Science \& Policy, 10(6), 499-511.

Ison, R. L., Blackmore, C. P., Collins, K. B., \& Furniss, P. (2007b). Systemic environmental decision making: Designing learning systems. Kybernetes, 36(9/10), 1340-1361.

Ison, R. L., Collins, K., Bos, J., Iaquinto, B. (2009). Transitioning to water sensitive cities in Australia: A summary of the key findings, issues and actions arising from five national capacity building and leadership workshops. Melbourne: NUWGP/IWC, Monash University. Available from http://www.watercentre.org/resources/publications/attachments/Creating\%20Water\%20 Sensitive\%20Cities.pdf. Accessed 11 Apr 2013.

Ison, R., Collins, K., Colvin, J., Jiggins, J., Roggero, P. P., Seddaiu, G., Steyaert, P., Toderi, M., \& Zanolla, C. (2011). Sustainable catchment managing in a climate changing world: new integrative modalities for connecting policy makers, scientists and other stakeholders. Water Resources Management, 25(15), 3977-3992.

Mostert, E., Pahl-Wostl, C., Rees, Y., Searle, B., Tàbara, D., \& Tippett, J. (2007). Social learning in European river-basin management: barriers and fostering mechanisms from 10 river basins. Ecology and Society, 12(1), 19 [online]. Available from http://www.ecologyandsociety.org/ vol12/iss1/art19/. Accessed 10 Oct 2012.

Muro, M., \& Jeffrey, P. (2008). A critical review of the theory and application of social learning in participatory natural resource management processes. Journal of Environmental Planning and Management, 51(3), 325-344.

OED (Oxford English Dictionary). (2012). Oxford University Press. Oxford.

Pahl-Wostl, C., Craps, M., Dewulf, A., Mostert, E., Tabara, D., \& Taillieu, T. (2007). Social learning and water resources management. Ecology and Society, 12(2), 5 [online]. Available at http://www.ecologyandsociety.org/vol12/iss2/art5/. Accessed 20 Oct 2012.

Pahl-Wostl, C., Mostert, E., \& Tàbara, D. (2008). The growing importance of social learning in water resources management and sustainability science. Ecology and Society, 13(1), 24. [online] Available at http://www.ecologyandsociety.org/vol13/iss1/art24/. Accessed 20 Oct 2012.

Raadgever, G. T., Mostert, E., \& van de Giesen, N. C. (2012). Learning from collaborative research in water management practice. Water Resources Management, 26(11), 3251-3266.

Redman, C. L., Morgan Grove, J., \& Kuby, L. H. (2004). Integrating social science into the longterm ecological research (LTER) network: Social dimensions of ecological change and ecological dimensions of social change. Ecosystems, 7, 161-171.

Reed, M. S., Evely, A. C., Cundill, G., Fazey, I., Glass, J., Laing, A., Newig, J., Parrish, B., Prell, C., Raymond, C., \& Stringer, L. C. (2010). What is social learning? Ecology and Society, 15(4), r1 [online]. Available from: http://www.ecologyandsociety.org/vol15/iss4/resp1/. Accessed 20 Oct 2012.

Rittell, H. W. J., \& Webber, M. M. (1973). Dilemmas in a general theory of planning. Policy Science, 4, 155-169.

Russell, D. B., \& Ison, R. L. (2007). The research-development relationship in rural communities: An opportunity for contextual science. In R. L. Ison \& D. B. Russell (Eds.), Agricultural extension and rural development: Breaking out of knowledge transfer traditions (pp. 10-31). Cambridge: Cambridge University Press.

Schön, D. A. (1995). Knowing in action: The new scholarship requires a new epistemology. Change, November/December, 27-34.

Schön, D. A., \& Rein, M. (1994). Frame reflection: Toward the resolution of intractable policy controversies. New York: Basic Books.

Scrase, J. I., \& Sheate, W. R. (2002). Integration and integrated approaches to assessment: What do they mean for the environment? Journal of Environmental Policy \& Planning, 4(4), 275-294.

Skidelsky, R. (2008). Morals and the meltdown [online]. Available from http://www.skidelskyr. com/site/article/morals-and-the-meltdown/. Accessed 14 June 2012. 
SLIM. (2004a). SLIM framework: Social learning as a policy approach for sustainable use of water. SLIM, Open University, Milton Keynes. Available at http://slim.open.ac.uk. Accessed 8 Sept 2012.

SLIM. (2004b). Stakeholders and stakeholding in integrated catchment management and sustainable use of water (SLIM Policy Brief No. 2). SLIM, Open University, Milton Keynes. Available from http://slim.open.ac.uk. Accessed 10 Sept 2012.

SLIM. (2004c). Introduction to SLIM publications for policy makers and practitioners. Introductory Policy Briefing. SLIM, Open University, Milton Keynes. Available at http://slim.open.ac.uk

SLIM (2004d). The role of learning processes in integrated catchment management and sustainable use of water (SLIM Policy Brief No. 6). SLIM, Open University, Milton Keynes. Available from http://slim.open.ac.uk. Accessed 11 Sept 2012.

SLIM (2004e). Ecological constraints in sustainable management of natural resources (SLIM Policy Briefing No. 1). SLIM, Open University, Milton Keynes. Available from http://slim. open.ac.uk. Accessed 11 Sept 2012.

Social Learning Group. (2001). Learning to manage global environmental risk. Cambridge, MA: MIT Press.

Steyaert, P., \& Jiggins, J. (2007). Governance of complex environmental situations through social learning: A synthesis of SLIM's lessons for research, policy and practice. Environmental Science and Policy, 10(6), 575-586.

Steyaert, P., Barzman, M. S., Brives, H., Ollivier, G., Billaud, J. P., \& Hubert, B. (2007). The role of knowledge and research in facilitating social learning among stakeholders in natural resources management in the French Atlantic coastal wetlands. Environmental Science and Policy, 10(6), 537-550.

UN. (2012). The future we want. Outcome of the UN Rio +20 conference. UN: Rio de Janeiro. Available at: https://rio20.un.org/sites/rio20.un.org/files/a-conf.2161-1_english.pdf.pdf. Accessed 1 Feb 2013.

UNEP. (2012). GEO5 global environmental outlook: Summary for policy-makers. UNEP: Nairobi. Available at http://www.unep.org/geo/pdfs/GEO5_SPM_English.pdf. Accessed 10 Jan 2013.

Wei, Y., Ison, R. L., Colvin, J., \& Collins, K. (2012). Reframing water governance in China: A multi-perspective study of an over-engineered catchment. Journal of Environmental Planning \& Management, 55(3), 297-318.

Wenger, E. (1998). Communities of practice: Learning, meaning and identity. Cambridge: Cambridge University Press.

Wenger, E., McDermott, R., \& Snyder, W. (2002). Cultivating communities of practice: A guide to managing knowledge. Boston: Harvard Business School Press.

Wilson, E. O. (1998). Consilience: The unity of science. New York: Knopf.

Woodhill, J., \& Röling, N. (1998). The second wing of the eagle: The human dimension in learning our way to more sustainable futures. In N. G. Röling \& M. A. E. Wagemakers (Eds.), Facilitating sustainable agriculture: Participatory learning and adaptive management in times of environmental uncertainty. Cambridge: Cambridge University Press.

Young, O. (2012). Navigating the sustainability transition: Governing complex and dynamic socioecological systems. In E. Brousseau, T. Dedeurwaerdere, P.-A. Jouvet, \& M. Willinger (Eds.), Global environmental commons: Analytical and political challenges in building governance mechanisms (pp. 80-104). Oxford: Oxford University Press. 